\title{
Metal-organic frameworks as hypergolic additives for hybrid rockets
}

\author{
Olivier Jobin ${ }^{\mathrm{a}}$, Cristina Mottillo ${ }^{\mathrm{b}}$, Hatem M. Titic ${ }^{\mathrm{c}}$, Joseph M. Marrett ${ }^{\mathrm{c}}$, Mihails \\ Arhangelskis $^{\mathrm{d}}$, Robin D. Rogers ${ }^{\mathrm{e},}$, Bachar Elzein ${ }^{\mathrm{f}}$, Tomislav Friščićc, ${ }^{*}$ and Étienne \\ Robert ${ }^{a, *}$ \\ ${ }^{a}$ Polytechnique Montréal, 2900 Boulevard Édouard-Montpetit, Montréal, QC H3T 1J4, Canada \\ ${ }^{b}$ ACSYNAM Inc., Montréal, QC H1P 1W1, Canada \\ ${ }^{c}$ McGill University, 801 Sherbrooke Street West, Montréal, QC H2L 0B7, Canada \\ ${ }^{d}$ University of Warsaw, 1 Pasteura Street, Warsaw, 02-093, Poland \\ e525 Solutions, P.O. Box 2206, Tuscaloosa, Al 35403, USA
}

${ }^{f}$ Reaction Dynamics, 45 Chemin de l'Aéroport, Saint-Jean-sur-Richelieu, QC J3B 7B5, Canada

*Corresponding authors: robin.rogers@525solutions.com,tomislav.friscic@mcgill.ca, etienne.robert@polymtl.ca

\begin{abstract}
Hybrid rocket propulsion can contribute to reduce launch costs by simplifying engine design and operation. Hypergolic propellants, i.e. igniting spontaneously and immediately upon contact between fuel and oxidizer, further simplify system integration by removing the need for an ignition system. Such hybrid engines could also replace currently popular hypergolic propulsion approaches based on extremely toxic and carcinogenic hydrazines. Here we present the first demonstration for the use of hypergolic metal-organic frameworks (HMOFs) as additives to trigger hypergolic ignition in conventional paraffin-based hybrid engine fuels. HMOFS are a recently introduced class of stable and safe hypergolic materials, used here as a platform to bring readily tunable ignition and combustion properties to hydrocarbon fuels. We present an experimental investigation of the ignition delay (ID, the time from first contact with an oxidizer to ignition) of blends of HMOFs with paraffin, using White Fuming Nitric Acid (WFNA) as the oxidizer. The majority of measured IDs are under $10 \mathrm{~ms}$, significantly below the upper limit of $50 \mathrm{~ms}$ required for functional hypergolic propellant, and within the ultrafast ignition range. A theoretical analysis of the performance of HMOFs-containing fuels in a hybrid launcher engine scenario also reveals the effect of the HMOF mass fraction on the specific impulse $\left(I_{s p}\right)$ and density impulse $\left(\rho I_{s p}\right)$. The use of HMOFs to produce paraffin-based hypergolic fuels results in a slight decrease of the $I_{s p}$ and $\rho I_{s p}$ compared to that of pure paraffin, similar to the effect observed with Ammonia Borane (AB), a popular hypergolic additive. HMOFs however have a much higher thermal stability, allowing for convenient mixing with hot liquid paraffin, making the manufacturing processes simpler and safer compared to other hypergolic additives such as AB.
\end{abstract}

Keywords metal-organic frameworks; hypergolic; hybrid rocket engine; specific impulse; propulsion; ignition 


\section{Introduction}

For small space technology companies, designing engines based on well established, albeit reliable, propellants is not always an attractive option, either due to their high toxicity, or requirements for complex engine designs. For example, hydrazine and its derivatives monomethylhydrazine (MMH) and unsymmetrical dimethylhydrazine (UDMH) [1] have been used for over 60 years as both satellite and rocket fuels due to their reliable combustion properties. However, their extreme toxicity and difficult handling, flights pose challenges and motivate a future ban for the use of these propellants in the European Union [2]. Other propellants systems, using liquid oxygen as the oxidizer and hydrogen or RP-1 as the fuel, are less toxic or non-toxic, but still require costly storage techniques and involve complex liquid-fueled cryogenic engines [3]. The cost of developing and using engines based on such propellants is an obstacle for the burgeonning companies aiming to democratize access to space and serve the burgeoning microsatellite industry. The desire to mitigate the impact of this emergent space industry on the environment, while making launches simpler, safer and less costly, calls for the development of innovative solutions to propulsion challenges adapted to small-scale launchers [4].

Recently developed propulsion approaches such as ion thrusters [5], water-splitting [6], and solar-powered engines [7] are simpler and safer than chemical propulsion, but are not suitable for all applications. For instance, ground-to-orbit missions as well as rapid-response spacecraft orbital manoeuvring and attitude correction require high thrust that these novel propulsion approaches cannot provide (e.g. the International Space Station carries ca. 1 ton of hypergolic hydrazines [8]). Consequently, chemical propulsion is still the choice for rocket launchers or in-orbit maneuvering $[9,10]$, with hybrid engines an attractive alternative to complex, and therefore more costly, liquid-fueled engines [11]. To replace polluting propellants and enable competitive small-scale launchers, new technologies [12-29] should match or exceed the performance metrics of currently used propulsion approaches. For instance, the characteristic velocity $\left(\mathrm{C}^{*}\right)$ is a measure of the combustion performance of a rocket propulsion system, independent of its nozzle. The typical $\mathrm{C}^{*}$ value for liquid oxygen and RP-1 is approximately $1774 \mathrm{~m} / \mathrm{s}$ at an optimal oxidizer-to-fuel ratio $(\mathrm{O} / \mathrm{F})$ of 2.24 , while it is of $1711 \mathrm{~m} / \mathrm{s}$ for the hypergolic, but highly toxic, combination of dinitrogen tetroxide $\left(\mathrm{N}_{2} \mathrm{O}_{4}\right)$ and a mixture of 50\% UDMH with $50 \%$ hydrazine at an $\mathrm{O} / \mathrm{F}$ of 2.00 [1]. Another important performance metric is the specific impulse $I_{s p}$, which is the change in velocity per unit of propellant consumed. Typical $I_{s p}$ values for commonly used propellant mixtures for liquid and solid engines are listed in Table 1 . The cryogenically stored propellant mixture of liquid oxygen (LOx) and liquid hydrogen $\left(\mathrm{LH}_{2}\right)$ has a theoretical $I_{s p}$ of $386 \mathrm{~s}$, which is generally considered to be the upper limit in chemical propulsion [1]. For comparison, solid rocket boosters (SRBs), the simplest rocket propulsion approach, can provide $I_{s p}$ values of approximately 260-265 s when mixtures of hydroxyl-terminated polybutadiene (HTPB), aluminum powder $(\mathrm{Al})$ and the oxidizer ammonium perchlorate (AP) are used [1,30,31]. These values are comparable to hypergolic hydrazine fuels, but the thrust of SRBs cannot be stopped nor 
throttled.

Table 1: Theoretical maximum $I_{s p}$ values for common propellants [1].

\begin{tabular}{lll}
\hline Fuel/Oxidizer & $I_{s p}[\mathrm{~s}]$ & Type of engines \\
\hline $\mathrm{LOx} /$ Liquid hydrogen $\left(\mathrm{LH}_{2}\right)$ & 386 & Liquid \\
$\mathrm{N}_{2} \mathrm{O}_{4} / \mathrm{UDMH}$ & 278 & Liquid, hypergolic \\
$\mathrm{RP}-1 / \mathrm{O}_{2}$ & 285 & Liquid \\
$\mathrm{HTPB}-\mathrm{AP}-\mathrm{Al}$ & $260-265$ & Solid \\
AMF-M315E & $231-248[30]$ & Monopropellant, hypergolic \\
$\mathrm{SHP} 163$ & $276[31]$ & Monopropellant, hypergolic \\
\hline
\end{tabular}

To fulfill its potential of reduced development costs and improving mechanical simplicity, hybrid rocket propulsion is in need of novel propellant systems to be competitive for launch vehicle applications, especially regarding specific and density impulses. This can be achieved with energy-dense additives in fuel grains made of solid hydrocarbons, including metal or organic hydrides and crystalline metals [32,33]. As an example, the incorporation of aluminum particles has been shown to improve the specific impulse of hybrid propellants relying on relatively weak oxidizers such as hydrogen peroxide or nitrous oxide [32]. Another way of making hybrid rockets more interesting is by inducing the hypergolic ignition of its fuel. Additives such as ammonia borane $(\mathrm{AB})$ can be included in a fuel matrix [25, 29, 33, 34]. On contact with the oxidizer, white fuming nitric acid (WFNA) for example, AB spontaneously ignites. A critical parameter here is the time elapsed from the first contact between the oxidizer and the fuel to the appearance of flames. This is called the ignition delay (ID) and low values are essential to ensure proper operation in hypergolic engines.

Here, we present a proof-of-principle demonstration of experimental and theoretical performance characteristics of a new class of hypergols based on a metal-organic framework (MOF) design [35-38]. We have recently demonstrated how the combination of metal nodes such as $\mathrm{Zn}^{2+}$ and $\mathrm{Co}^{2+}$, with linkers based on suitably substituted imidazoles (e.g. 2-vinyl and 2-acetylene-substituted imidazoles, HVIm and HAIm, respectively, Figure 1a), results in zeolitic imidazolate frameworks (ZIFs) [39,40] exhibiting hypergolic behavior (Figure 1b, c).

Specifically, these hypergolic MOFs (HMOFs) were found to exhibit ultrashort IDs (below $50 \mathrm{~ms}$, and often below $5 \mathrm{~ms}$ ) when in contact with traditional oxidizers such as white and red fuming nitric acids (WFNA, RFNA, respectively), along with heats of combustion $\left(\Delta H_{C}\right)$ around $-8700 \mathrm{~kJ} / \mathrm{mol}$, with volumetric energy density $\left(E_{v}\right)$ of $36.3 \mathrm{~kJ} / \mathrm{cm}^{3}$. While these values are higher than for $\mathrm{MMH}\left(\Delta H_{C}=-1304 \mathrm{~kJ} / \mathrm{mol} ; E_{v}=24.7 \mathrm{~kJ} / \mathrm{cm}^{3}\right)$ or UDMH $\left(\Delta H_{C}=-1979 \mathrm{~kJ} / \mathrm{mol} ; E_{v}=25.9 \mathrm{~kJ} / \mathrm{cm}^{3}\right)$ [39, 41], HMOFs are also attractive as readily handled solids, stable upon extended storage, which do not exhibit ignition below at least 250-325 ${ }^{\circ} \mathrm{C}$ [40], compared to $\mathrm{AB}$ who can self-ignites at temperature as low as $75{ }^{\circ} \mathrm{C}$ [42], since the resulting fuel mixture is easily handled and avoids unpredictable thermal responses.

As the next step in developing MOFs as a platform for new hypergolic systems, we demonstrate here that these HMOFs are highly effective additives to induce hypergolicity 

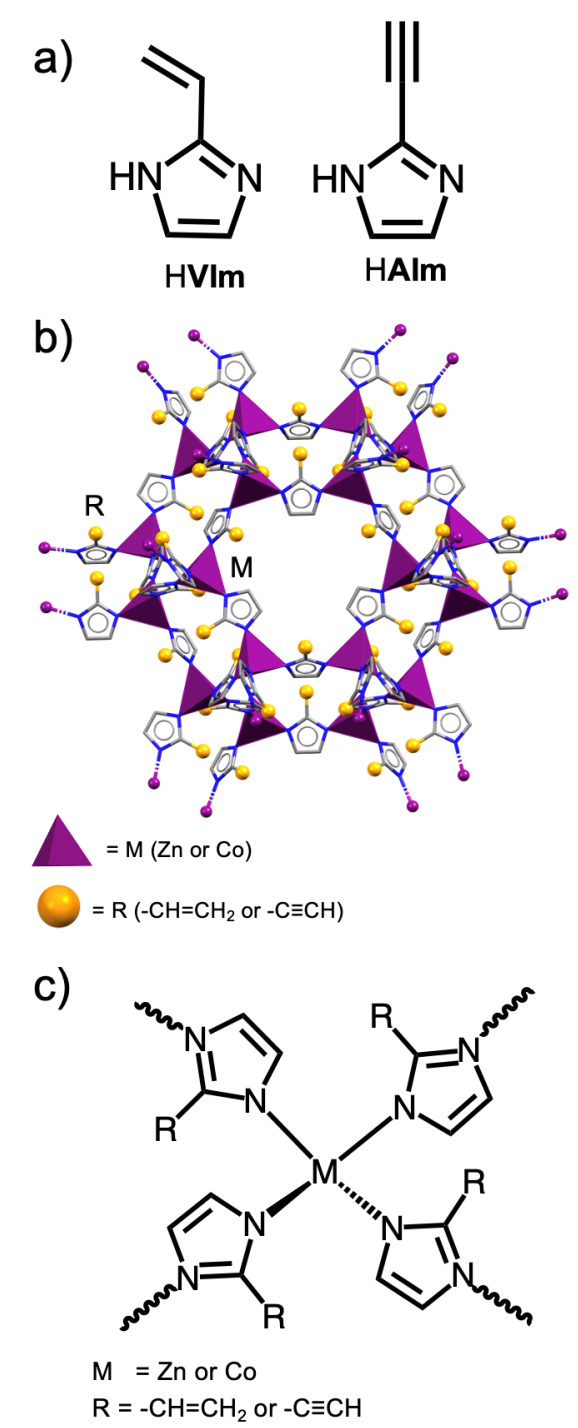

Figure 1: a) Schematic representation of the ligand used in this study. b) A general illustration of the HMOFs. c) A Schematic diagram of the assembly of metal ions and organic linkers to form HMOFs.

into conventional, non-hypergolic hybrid engine paraffin fuels. The hypergolic and energetic properties of HMOFs will be compared against additives currently used to bring these characteristics to hybrid fuels; $\mathrm{AB}$ and $\mathrm{Al}$ [43], respectively.

\section{Materials and methods}

\section{$2.1 \quad$ Hypergolic additives}

The HMOFs used in this study were selected based on their hypergolic character. To ensure the safe operation of rocket engines using hypergolic propellants, an ID below $50 \mathrm{~ms}$ [44] is generally considered desirable, with ID below $10 \mathrm{~ms}$ required for dynamic altitude control systems [33]. However, with the hybrid propulsion approach, less stringent threshold can be used as fuel is in a solid state and in a predetermined geometry. As a result, flooding 
of the engine is harder to achieve compared to a liquid engine, decreasing the likelihood of dramatic consequence in case of a high ID. It is not possible to add more fuel in the chamber than the exposed surface of the grain, making them safer than hypergolic liquid engines.

The IDs of hypergolic hybrid additives documented in the literature, including the HMOFs used here, are provided in Table 2. Previously reported RFNA and WFNA ignition drop tests on pure HMOFs samples revealed that the materials generated from HAIm exhibit the shortest ID values, at or below $5.0 \mathrm{~ms}$. The HMOFs based on HVIm exhibit longer IDs, with $\mathrm{Co}(\mathbf{V I m})_{2}$ at $11.0(5.0) \mathrm{ms}$, and its zinc and cadmium analogues above $10 \mathrm{~ms}$. These values compare advantageously with those of currently available hypergolic propellants or additives used for blending in hydrocarbon or polymeric matrices. More specifically, the HAIm-based HMOFs exhibit IDs matching that of hydrazines and AB. Even the worst-performing $\mathrm{Cd}(\mathbf{V I m})_{2}$ exhibits an ID of 35.0(1.0) ms at atmospheric pressure, notably shorter than the $50 \mathrm{~ms}$ target [40].

Table 2: Ignition delays of hypergolic additives and HMOFs with WFNA as the oxidizer.

\begin{tabular}{ccccc}
\hline Category & Additive & $\begin{array}{c}\text { Avg. Ignition } \\
\text { Delay }[\mathrm{ms}]\end{array}$ & $\begin{array}{c}\text { Standard } \\
\text { Deviation [ms] }\end{array}$ & Ref. \\
\hline Common & $\mathrm{AB}$ & 2.0 & - & {$[19]$} \\
hypergolic & Hydrazine & 3.1 & - & {$[45]$} \\
additive & Lithium-Aluminum-Hydride ${ }^{\dagger}$ & 31.3 & 7.2 & {$[46]$} \\
\hline \multirow{2}{*}{ Metal-Organic } & $\mathrm{Co}(\mathbf{V I m})_{2}$ & 11.0 & 5.0 & {$[40]$} \\
Framework & $\mathrm{Zn}(\mathbf{V I m})_{2}$ & 29.0 & 1.0 & - \\
& $\mathrm{Co}(\mathbf{A I m})_{2}$ & 2.0 & 1.0 & {$[40]$} \\
& $\mathrm{Zn}(\mathbf{A I m})_{2}$ & 2.0 & 1.0 & {$[40]$} \\
\hline
\end{tabular}

$\dagger$ Test conducted at a pressure of $0.10 \mathrm{MPa}$ with analytical reagent-grade nitric acid (69.3 wt.\%)

The heat of formation $\left(\Delta \mathrm{H}_{f}^{0}\right)$ of HMOFs were determined theoretically, using periodic density-functional theory (DFT) calculations, within the plane-wave DFT code CASTEP 16.1 [47]. The structures of HMOFs and elements in their standard reference states ( $\mathrm{Zn}$, and Co metals, graphite, $\mathrm{H}_{2}, \mathrm{~N}_{2}$ and $\mathrm{O}_{2}$ gases) were geometry-optimized using PBE [48] functional combined with Grimme D2 dispersion correction [49]. The standard enthalpies of formation were then derived by subtracting the electronic energies of the elements in their reference states from the energies of the HMOF structures, taking into account the stoichiometric coefficients. The calculated heats of formation are given in Table 3.

Table 3: Selected properties of HMOFs and other hypergolic/energetic additives used here for comparison.

\begin{tabular}{lccc}
\hline Fuel Additive & $\begin{array}{c}\text { Chemical } \\
\text { Formula }\end{array}$ & Density $\left[\mathrm{g} / \mathrm{cm}^{3}\right]$ & $\Delta \mathrm{H}_{f}^{0}[\mathrm{~kJ} / \mathrm{mol}]$ \\
\hline $\mathrm{Co}(\mathbf{V I m})_{2}$ & $\mathrm{Co}\left(\mathrm{C}_{5} \mathrm{H}_{5} \mathrm{~N}_{2}\right)_{2}$ & 0.944 & -1.3 \\
$\mathrm{Zn}(\mathbf{V I m})_{2}$ & $\mathrm{Zn}\left(\mathrm{C}_{5} \mathrm{H}_{5} \mathrm{~N}_{2}\right)_{2}$ & 0.976 & -51.5 \\
$\mathrm{Co}(\mathbf{A I m})_{2}$ & $\mathrm{Co}\left(\mathrm{C}_{5} \mathrm{H}_{3} \mathrm{~N}_{2}\right)_{2}$ & 0.985 & 445.8 \\
$\mathrm{Zn}(\mathbf{A I m})_{2}$ & $\mathrm{Zn}\left(\mathrm{C}_{5} \mathrm{H}_{3} \mathrm{~N}_{2}\right)_{2}$ & 0.996 & 397.1 \\
\hline
\end{tabular}




\subsection{Experimental section}

\subsubsection{Sample preparation}

Hypergolic ignition tests on mixtures of HMOFs and paraffin were performed using $\mathrm{Co}(\mathbf{V I m})_{2}$, $\mathrm{Zn}(\mathbf{V I m})_{2}$ and $\mathrm{Co}(\mathbf{A I m})_{2}$ as the hypergolic ignition additive, and FR5560 paraffin wax (The Candlewic Company, USA) as the matrix. The fuel samples were in the form of cylindrical pellets of approximately $300 \mathrm{mg}$, exposed to a single droplet of WFNA (10 $\mu \mathrm{L}$ volume) deposited using a glass syringe held approximately $150 \mathrm{~mm}$ above the pellets.

Ignition was investigated for three different sample configurations (Configuration I, II and III), differring in how the HMOF and the FR5560 wax are combined. Configuration I was based on a fuel pellet made from homogeneous blend of 80 wt.\% FR5560 wax paraffin and 20 wt.\% HMOF. Configuration II consisted of a fuel pellet with a thin layer (ca. $10 \mathrm{mg}$ by weight) of a HMOFs placed on top of it. In Configuration III, a central hole was drilled in the pellets and filled with ca. $10 \mathrm{mg}$ of a HMOF.

Samples for ignition testing in Configuration I were made by melting the paraffin on a hot plate, followed by addition of a HMOF and gentle stirring until a homogeneous liquid is obtained. The blend was then poured into an aluminum mold and hand-pressed. Before ignition tests, the pellet surface was sanded using 80-grit sandpaper to ensure a consistent contact surface and exposure of hypergolic additives to the oxidizer droplet. Pellets were made one by one and, unless otherwise specified, ignition tests were performed in triplicate.

Samples for ignition testing in Configuration II were prepared following the same steps as Configuration I, followed by of pressing ca. $10 \mathrm{mg}$ of a HMOF powder on the top surface of the pellet.

Samples for ignition testing in Configuration II were prepared with the same steps as Configuration I, in the addition of pressing $10 \mathrm{mg}$ of HMOF powder on its top surface. Samples in Configuration III were prepared by following the same steps as for Configuration I. After solidification, a small hole of ca. $2 \mathrm{~mm}$ diameter and a depth of $4 \mathrm{~mm}$ was drilled in the center of the pellet, into which $10 \mathrm{mg}$ of HMOFs powder was placed and gently pressed. Pellets for studies in Configurations II and III were based either on pure paraffin, or on a mixture containing 20 wt.\% HMOFs with 80 wt.\% paraffin. In the latter case, both propellants were mixed together in the same way as for Configuration I.

\subsubsection{Droplet ignition tests}

The ID was measured from the sequence of events following the impact of an oxidizer droplet on fuel samples, recorded using a Fastcam Mini AX200 high-speed camera (Photron, Japan) operating at 10,000 frames per second (fps). A $105 \mathrm{~mm}$ Sigma lens was used, set at an F-number of 1.4 , with an exposure of $1 / 10000 \mathrm{~s}$ and an OSL2 high-intensity light source (Thorlabs, USA). The ID was measured as the time interval between the initial contact of the droplet with the upper surface of a fuel pellet and the visible first emission of light. Previous experiments comparing visible light emission and $\mathrm{OH}^{*}$ chemiluminescence in droplet ignition 
tests have revealed that the former can reliably be used to capture the onset of combustion $[34]$.

\subsubsection{Ignition of mixtures of HMOFs and paraffin}

A sequence of images representative of the ignition of samples of pure HMOFs is illustrated in Figure 2. In each sequences, the second image captures the first contact between the oxidizer droplet and the sample, while the image directly after represents the first recorded frame where ignition is visible. Any subsequent images are shown as a means to illustrate the intensity and character of the flame. In the case of $\mathrm{Zn}(\mathbf{V I m})_{2}$ (Figure 2b), only small sparks were perceptible, in contrast to the sustained flames observed with the two other HMOFs.

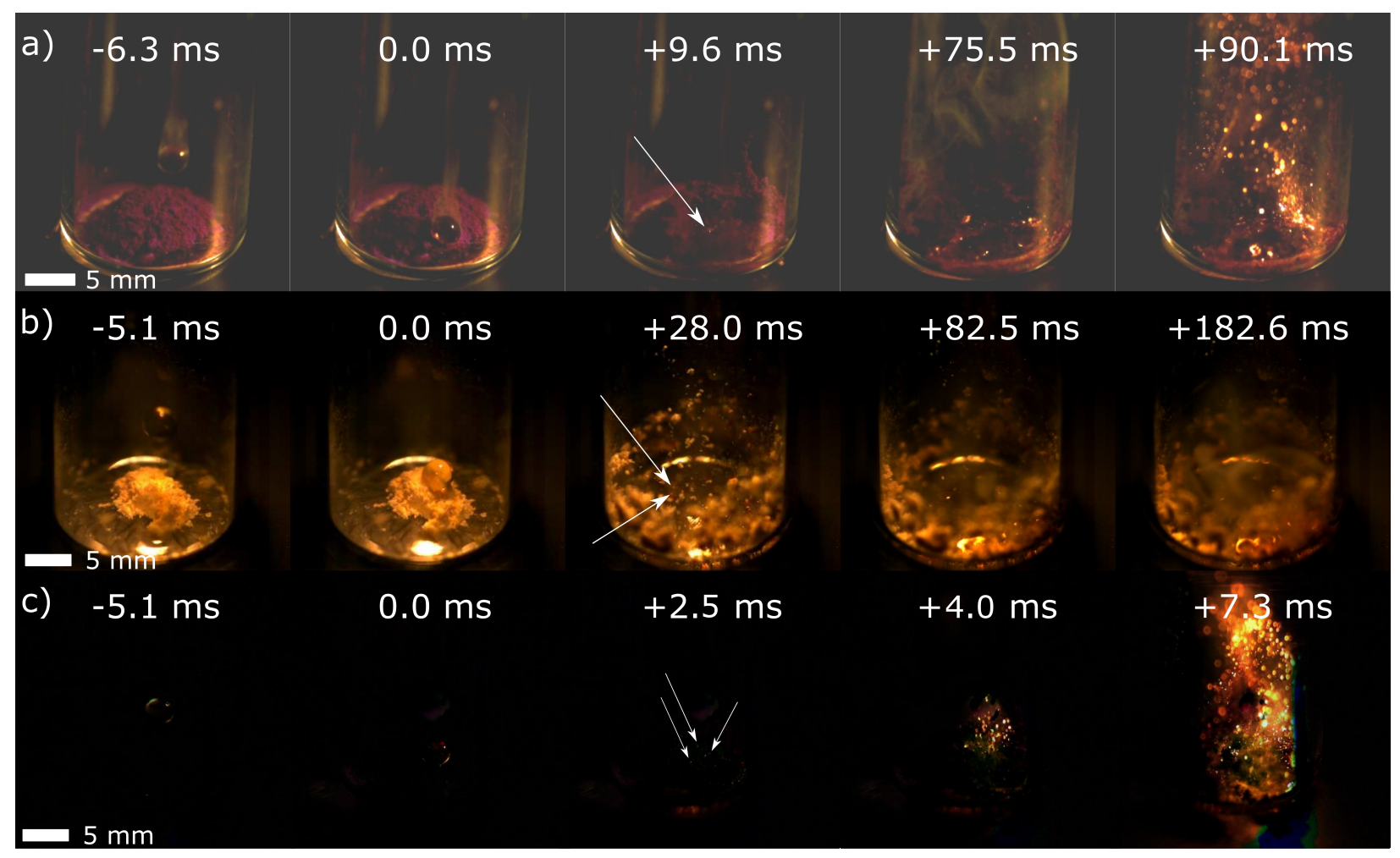

Figure 2: Droplet ignition tests on a) pure $\mathrm{Co}(\mathbf{V I m})_{2}$, b) pure Zn $(\mathbf{V I m})_{2}$, and c) pure $\mathrm{Co}(\mathbf{A I m})_{2}$ using ca. $10 \mathrm{mg}$ of HMOF powder samples and WFNA as the oxidizer. The location of the first ignition is marked with the white arrow. Picture in c) were digitally modified to remove reflections on the glass vial. The original videos are available online as supplemental material.

For the ignition tests conducted on samples containing the paraffin and a HMOF, the results are summarized in Table 4.

\subsubsection{Periodic DFT calculations}

Periodic density functional theory (DFT) calculations were used to determine the standard enthalpies of formation of ZIF materials. In order to calculate the $\Delta \mathrm{H}_{f}^{0}$ values, electronic 
Table 4: Ignition delay of tested fuel formulations and configuration using WFNA as the oxidizer. Configuration I $=$ Fuel pellet, Configuration II $=$ HMOF powder layer on fuel pellet, Configuration III $=$ HMOF powder-filled hole in fuel pellet. NT $=$ Not Tested. $-=$ No ignition.

\begin{tabular}{|c|c|c|c|c|}
\hline $\mathrm{MOF}$ & Configuration & Pellet Content & $\begin{array}{l}\text { Avg. Ignition } \\
\text { Delay [ms] }\end{array}$ & $\begin{array}{c}\text { Standard } \\
\text { Deviation }[\mathrm{ms}]\end{array}$ \\
\hline \multirow{6}{*}{$\mathrm{Co}(\mathbf{V I m})_{2}$} & & 80 wt.\% FR5560 wax/ 20 wt.\% Co(VIm $)_{2}$ & - & - \\
\hline & & 50 wt.\% FR5560 wax/ 50 wt. $\%$ Co(VIm) $)_{2}$ & - & - \\
\hline & \multirow{2}{*}{ II } & ${ }^{-10} \overline{0}$ wt. $\% \overline{\mathrm{F}} \overline{\mathrm{R}} \overline{5} 5 \overline{6} 0$ wax & $1 \overline{2} . \overline{9}$ & $1 \overline{0} . \overline{7}$ \\
\hline & & 80 wt.\% FR5560 wax/ 20 wt. $\%$ Co(VIm) $)_{2}$ & 13.3 & 5.3 \\
\hline & & $10 \overline{0}$ wt. $\% \overline{\mathrm{F}} \overline{\mathrm{R}} 55 \overline{6} 0$ wax & $6 . \overline{3}$ & $\overline{1} . \overline{6}$ \\
\hline & & 80 wt. $\%$ FR5560 wax/ 20 wt. $\%$ Co(VIm $)_{2}$ & 8.3 & 0.1 \\
\hline \multirow{5}{*}{$\mathrm{Zn}(\mathbf{V I m})_{2}$} & \multirow{5}{*}{$\begin{array}{r}\mathrm{I} \\
---\frac{-}{\mathrm{II}} \\
--- \\
\text { III }\end{array}$} & 80 wt.\% FR5560 wax/ 20 wt. $\%$ Zn(VIm $)_{2}$ & NT & NT \\
\hline & & 50 wt.\% FR5560 wax/ 50 wt. $\% \mathrm{Zn}(\mathbf{V I m})_{2}$ & - & - \\
\hline & & $10 \overline{\text { wt. }} \overline{\mathrm{F}} \overline{\mathrm{R}} \overline{5} 5 \overline{6} 0 \mathrm{wax}-\overline{-}$ & - & - \\
\hline & & 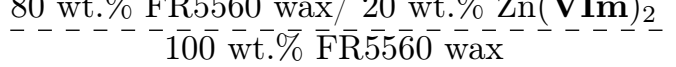 & & \\
\hline & & 80 wt.\% FR5560 wax/ 20 wt. $\%$ Zn(VIm $)_{2}$ & - & - \\
\hline \multirow{6}{*}{$\mathrm{Co}(\mathbf{A I m})_{2}$} & & 80 wt. $\%$ FR5560 wax/ 20 wt. $\%$ Co(AIm $)_{2}$ & - & - \\
\hline & & 50 wt. $\%$ FR5560 wax $/ 50$ wt. $\% \mathrm{Co}(\mathbf{A I m})_{2}$ & $7.0^{\ddagger}$ & $1.8^{\ddagger}$ \\
\hline & \multirow[t]{2}{*}{ II } & $10 \overline{0}$ wt. $\% \overline{\mathrm{F}} \overline{\mathrm{R}} 55 \overline{6} 0$ wax & $2 . \overline{3}$ & $0 . \overline{1}$ \\
\hline & & 80 wt.\% FR5560 wax/ 20 wt. $\% \mathrm{Co}(\mathbf{A I m})_{2}$ & NT & NT \\
\hline & \multirow{2}{*}{ III } & $1 \overline{0} \overline{\mathrm{wt}} . \% \overline{\mathrm{F}} \overline{\mathrm{R}} 55 \overline{6} 0 \mathrm{wax}$ & $1 . \overline{8}$ & $0 . \overline{7}$ \\
\hline & & 80 wt. $\%$ FR5560 wax $/ 20$ wt. $\%$ Co(AIm $)_{2}$ & NT & NT \\
\hline
\end{tabular}

$\ddagger$ Tested in the form of powder since the mixture was too brittle to form a pellet.

energies of elements in their standard states ( $\mathrm{Zn}$ and Co metals, graphite, $\mathrm{H}_{2}, \mathrm{~N}_{2}$ and $\mathrm{O}_{2}$ gases) had to be combined with the electronic energies of ZIF structures from our previous publication [40]. Calculations were performed with the plane wave DFT code CASTEP 16.1 [47]. The crystal structures of ZIFs, Zn, Co and Cd metals were converted into CASTEP input format using the program CIF2Cell [50]. For the elements present in the gas phase under standard conditions $\left(\mathrm{H}_{2}, \mathrm{~N}_{2}\right)$ the respective molecules were placed in a $30 \times 30 \times 30$ $\AA$ cubic box, sufficiently large to prevent the interaction for the periodic images of gas molecules. Calculations were performed using a PBE [48] functional combined with Grimme D2 dispersion correction [49]. The plane-wave basis set was truncated at $750 \mathrm{eV}$ cutoff, and norm-conserving pseudopotentials were used to attenuate the core regions of electron density. In the case of crystal structures, optimization involved relaxation of atom coordinates and unit cell parameters, subject to the symmetry constraints of the corresponding space groups. In the case of gas phase molecules, the dimensions of the cubic box were kept fixed throughout the optimization. The optimization was deemed converged upon satisfying the following criteria: a maximum energy change of $10-5 \mathrm{eV} /$ atom, a maximum force on atom of 0.01 $\mathrm{eV} / \AA$, a maximum atom displacement of $0.001 \AA$, and a residual stress of 0.05 GPa (only for variable cell optimization for crystal structures). The resulting energies were used to compute the enthalpies of formation according to the following reaction equations:

$$
\begin{aligned}
& \mathrm{Co}(\mathbf{V I m})_{2}: \mathrm{Co}_{(s)}+10 C_{(s)}+2 N_{2(g)}+5 H_{2(g)} \rightarrow C o\left(C_{5} H_{5} N_{2}\right)_{2(s)} \\
& Z n(\mathbf{V I m})_{2}: Z n_{(s)}+10 C_{(s)}+2 N_{2(g)}+5 H_{2(g)} \rightarrow Z n\left(C_{5} H_{5} N_{2}\right)_{2(s)}
\end{aligned}
$$




$$
\begin{aligned}
& \mathrm{Co}(\mathbf{A I m})_{2}: \mathrm{Co}_{(s)}+10 C_{(s)}+2 N_{2(g)}+3 H_{2(g)} \rightarrow C o\left(C_{5} H_{3} N_{2}\right)_{2(s)} \\
& Z n(\mathbf{A I m})_{2}: Z n_{(s)}+10 C_{(s)}+2 N_{2(g)}+3 H_{2(g)} \rightarrow Z n\left(C_{5} H_{3} N_{2}\right)_{2(s)}
\end{aligned}
$$

\subsection{Ignition Results and Discussion}

\subsubsection{Ignition tests of blends with $\mathrm{Co}(\mathrm{VIm})_{2}$}

Drop tests on pellets containing 20 wt.\% Co(VIm) $)_{2}$ with 80 wt.\% paraffin in Configuration I generated only discrete, small sparks on the pellet surface, with no definitive ignition. Moreover, the sparks were difficult to distinguish from light reflection on the surface of the WFNA droplet, preventing uthe clear measurement of IDs. This difficulty to observe flames in Configuration I is most likely caused by the very fine granulometry of the HMOF powders used to prepare the samples, with an average particle size on the order of $0.1 \mu \mathrm{m}$ [40]. When embedded in a paraffin matrix, the weak outgassing produced by these very small particles is quenched by the oxidizer layer resting on top of the fuel pellet.

To achieve ignition, we explored using a single pellet containing $50 \mathrm{wt} . \% \mathrm{Co}(\mathbf{V I m})_{2}$ and 50 wt.\% paraffin wax. In this case, a strong reaction occurred on the surface of the pellets, with bubbles and gas generation $100.8 \mathrm{~ms}$ after the first contact with the WFNA droplet. Several seconds after the test, each pellet was thoroughly examined: a black layer of burned HMOFs was present on its surface, as well as traces of melted paraffin-MOFs mixture.

Drop tests in Configuration II revealed ignition in all cases, accompanied with large bursts of flame visible in half of all the tests performed. Bursts of flame occurred mainly on top of the pellets and are attributed to the hypergolic ignition of the HMOF upon contact with WFNA. Overall, the experiments suggest that the paraffin did not react with WFNA. We speculated that, due to the small particle size and thin layer HMOF, hypergolic ignition might not generate enough heat to cause paraffin ignition.

To test this hypothesis, we explored hypergolic ignition in Configuration III. In 5 out of 6 cases, using either neat paraffin or a blend of paraffin and $\mathrm{Co}(\mathbf{V I m})_{2}$ in respective weight ratio 80:20, sparks were produced, followed by bursts of flames resembling those observed for Configuration II. However, the bursts of flame in Configuration III were also followed by continuous combustion (up to $2.5 \mathrm{~s}$ ) that was attributed to the paraffin, first reacting with the leftover WFNA and then with ambient air. Using $5 \mathrm{mg} \mathrm{Co}(\mathbf{V I m})_{2}$ instead of $10 \mathrm{mg}$ in this configuration did not lead to the ignition of the paraffin.

Notably, the ignition with $\mathrm{Co}(\mathbf{V I m})_{2}$ in Configuration III, using either pure paraffin and or HMOF-paraffin blends as the pellet material, produced remarkably short average IDs of respectively $6.3(1.6) \mathrm{ms}$ and $8.3(0.1) \mathrm{ms}$. These values are $52 \%$ and $37 \%$ shorter, respectively, than the IDs seen in Configuration II, confirming that spatially concentrated HMOF will not only enable paraffin ignition, but also reduce the ID value. Furthermore, eight out of twelve tests in Configurations II and III were observed to ignite with IDs below $10 \mathrm{~ms}$, which is considered to be the target value for dynamic altitude control systems [33]. 


\subsubsection{Ignition tests on blends with $\mathrm{Zn}(\mathrm{VIm})_{2}$}

Tests carried with $\mathrm{Zn}(\mathbf{V I m})_{2}$ did not lead to the ignition of the pellets in any of the three configurations. In some cases, mostly under configurations II and III, a reaction occurred on the surface of the pellet: fumes were generated and a layer of black material was observed to form. Furthermore, small sparks similar to those observed on pure $\mathrm{Zn}(\mathbf{V I m})_{2}$ powder (Figure 2c) were observed. However, due to the difficulty of distinguishing the light emitted by the sparks from the light refracted by the WFNA droplet, ID values are not reported.

A single droplet test was performed with a pellet containing 50 wt.\% paraffin wax and 50 wt.\% Zn(VIm $)_{2}$ under configuration I. Since sparks were not observed in that case, ignition of mixtures containing 20 wt. $\%$ of $\mathrm{Zn}(\mathbf{V I m})_{2}$ was not tested.

\subsubsection{Ignition tests on blends with $\mathrm{Co}(\mathrm{AIm})_{2}$}

As $\mathrm{Co}(\mathbf{A I m})_{2}$ has previously been demonstrated to be the so far most rapidly igniting HMOF, tests were conducted only in Configurations II and III, using a neat paraffin wax pellet. Tests in Configuration I could not be done using a pellet, as the mixture of HMOF and paraffin was too brittle. Consequently, the drop ignition tests in this configuration were conducted on a mixture of $\mathrm{Co}(\mathbf{A I m})_{2}$ and paraffin powders. Out of the three tests carried that way, two led to hypergolic ignition lasting approximately 2 seconds, making $\mathrm{Co}(\mathbf{A I m})_{2}$ the only HMOF that readily ignited even in a homogeneous powder mixture with paraffin (Figure 3).

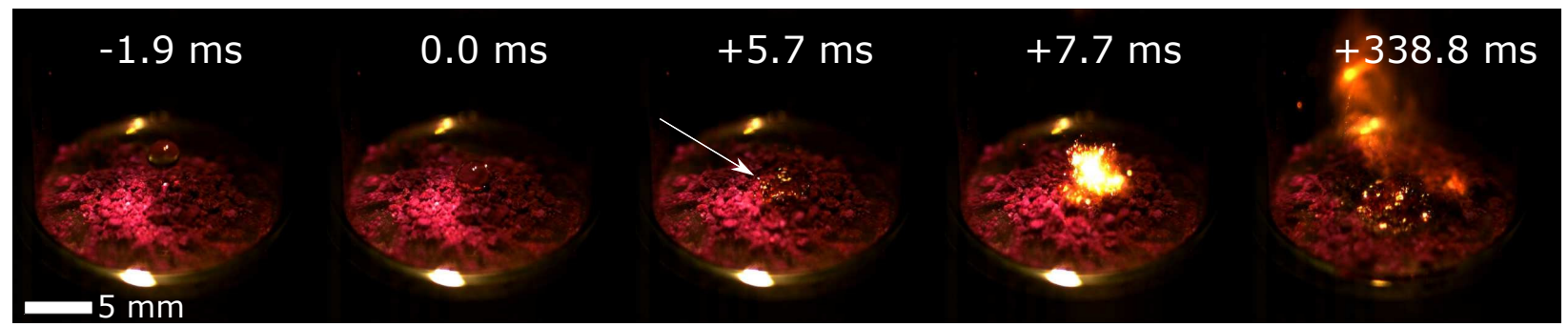

Figure 3: Example of a ignition drop test on 50 wt.\% FR5560 wax / 50 wt.\% Co(AIm $)_{2}$ using WFNA as the oxidizer. The location of the first ignition is marked with the white arrow. Full sequence available on supplement material.

Tests carried with $\mathrm{Co}(\mathbf{A} \mathbf{I m})_{2}$ in Configuration II all revealed rapid ignition, with an average ID of $2.3(0.1) \mathrm{ms}$, which corresponds to a reduction of $82 \%$ compared to $\mathrm{Co}(\mathbf{V I m})_{2}$ in the same configuration. In addition to a remarkably short ID values, well under the 10 ms target value, paraffin ignition and burning was observed in two out of three tests (Figure 4). These results clearly demonstrate that the heat released by hypergolic ignition of a thin layer of $\mathrm{Co}(\mathbf{A} \mathbf{I m})_{2}$ can be used to ignite solid paraffin fuel underneath.

Ignition drop tests with $\mathrm{Co}(\mathbf{A I m})_{2}$ in Configuration III gave the shortest ID values, leading to an average of $1.8(0.7) \mathrm{ms}$. This value represents a decrease of $71 \%$ compared to the results obtained with $\mathrm{Co}(\mathbf{V I m})_{2}$ in the same configuration. Notably, following the initial hypergolic ignition of $\mathrm{Co}(\mathbf{A} \mathbf{I m})_{2}$, paraffin ignition was observed in all cases (Figure 5). 


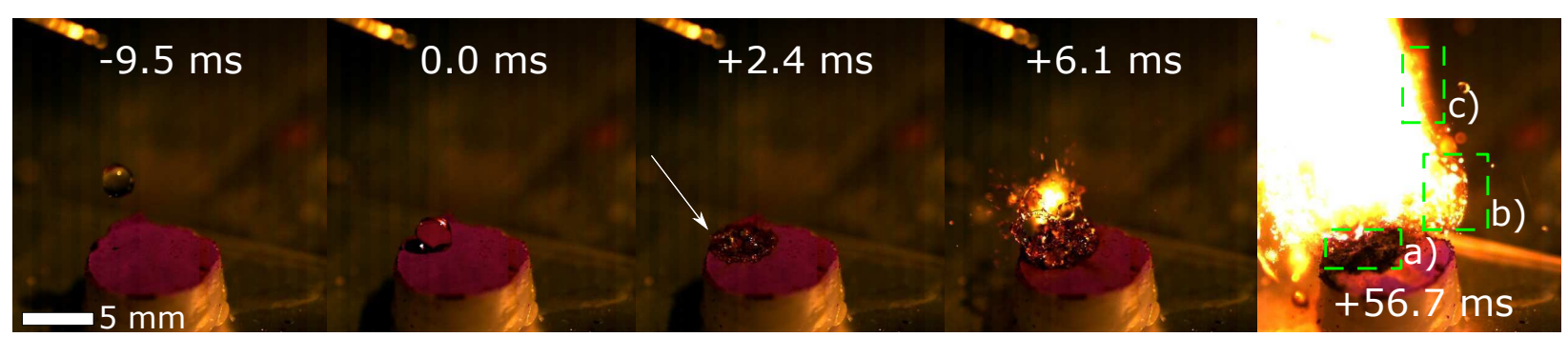

Figure 4: Example of an ignition drop test on a FR5560 wax pellet covered with a thin 10 mg layer of $\mathrm{Co}(\mathbf{A I m}) 2$ (Configuration II), using WFNA as the oxidizer. The location of the first ignition is marked with the white arrow. a) Burned paraffin and HMOFs. b) Burning HMOF. c) Paraffin flame. Full sequence available in supplemental material.

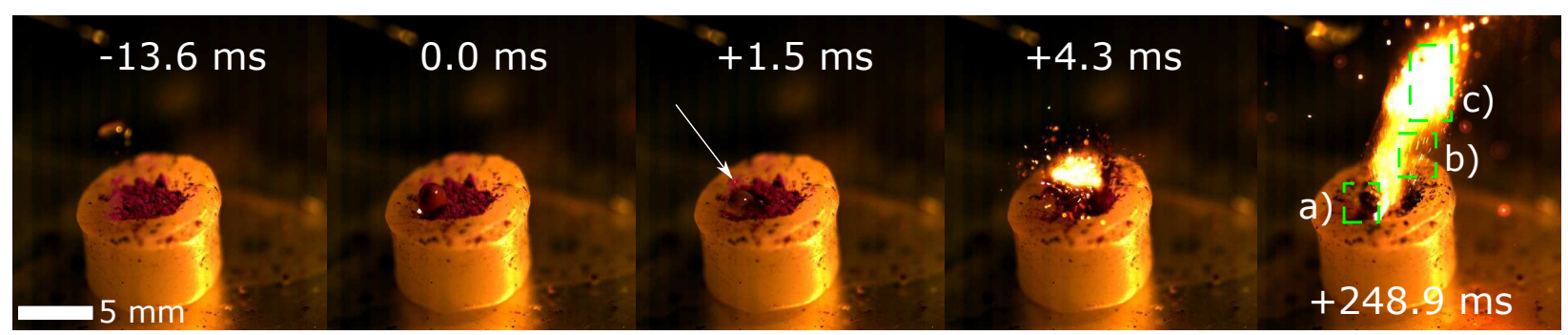

Figure 5: Drop tests on neat paraffin wax pellet with a $10 \mathrm{mg}$ of $\mathrm{Co}(\mathbf{A I m})_{2}$ located in a hole in the center, using WFNA as the oxidizer. The location of the first ignition is marked with the white arrow. a) Burned paraffin and HMOF. b) Burning HMOF powder. c) Paraffin flame. Full sequence available in supplemental material.

\section{Theoretical performance}

The use of MOFs as modular propellant fuels and additives is contingent upon their projected performance as components of fuel blends useful for practical engine designs. In that context, we present here the theoretical performance of HMOFs as additives for hypergolic ignition in hybrid propulsion systems based on paraffin fuel. The thermo-chemical simulations considered solid paraffin wax for the fuel grain matrix, and the performance characteristics were calculated for variable $\mathrm{HMOF}$ additive mass fractions and $\mathrm{O} / \mathrm{F}$ ratios. A paraffin-based propellant system was selected for modeling as its liquefying characteristics results in the high regression rates needed for high-thrust hybrid rocket engines.

The $I_{s p}$ and density specific impulse $\left(\rho I_{s p}\right)$ of hybrid paraffin-based fuel mixtures containing HMOFs were calculated using the NASA-CEA software [51]. The values obtained were then compared to those for paraffin fuels containing $\mathrm{AB}$ and aluminum for reference. $\mathrm{AB}$ in a paraffin matrix can yield hypergolic ignition [14, 19,34], just as our proposed use of HMOFs. Although aluminum particles as fuel additives do not yield hypergolicity, they were considered here for comparison as energetic rocket fuel additives [43]. The oxidizers investigated were WFNA, LOx and high-test peroxide (HTP, $\mathrm{H}_{2} \mathrm{O}_{2}$ at 90 wt.\% concentration in $\mathrm{H} 2 \mathrm{O})$. The absolution combustion chamber pressure considered was $6.89 \mathrm{MPa}(1000$ psia) and the exhaust gases were assumed to be in chemical equilibrium conditions and 
perfectly expanded to atmospheric pressure. The properties of the oxidizers were retrieved from NASA-CEA, with the densities used for calculations being $1.141 \mathrm{~g} / \mathrm{cm}^{3}$ for LOx, 1.513 $\mathrm{g} / \mathrm{cm} 3$ for WFNA and $1.392 \mathrm{~g} / \mathrm{cm}^{3}$ for HTP. The chemical formula of the paraffin used for the analysis is $\mathrm{C}_{32} \mathrm{H}_{66}$ with an approximate density of $0.90 \mathrm{~g} / \mathrm{cm}^{3}$. The properties of paraffin, aluminum and AB were extracted from the NASA-CEA library whereas those of the HMOFs were measured experimentally and reported earlier in Table 3.

\subsection{Performance of pure HMOFs}

For comparison purposes, theoretical performances of pure fuel matrices made of paraffin and HTPB without energetic or hypergolic additives are shown in Figure 6 and Table 5, as a function of the $\mathrm{O} / \mathrm{F}$ ratio for various oxidizers. When used as the oxidizer, LOx used as oxidizer provides the best specific impulse among those presented with a maximal value of approximately 300s. The use of WFNA allowed maximal values of $I_{s p}$ of approximately 265s whereas engines using $\mathrm{H}_{2} \mathrm{O}_{2}$ could achieve an $I_{s p}$ of almost 290s.

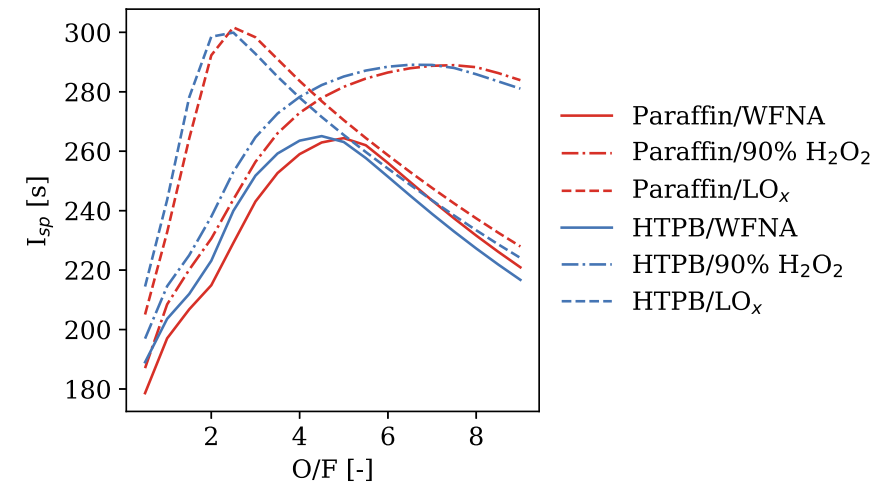

Figure 6: Theoretical performances of common propellants and oxidizers used in hybrid rocket engines. Equilibrium conditions, chamber pressure of 6.89 $\mathrm{MPa}$ and perfect expansion to atmospheric conditions.

Table 5: Theoretical performances of commonly used fuels and oxidizer combinations at their optimum $\mathrm{O} / \mathrm{F}$ ratio.

\begin{tabular}{ccccc}
\hline Fuel & Oxidizer & $\mathrm{O} / \mathrm{F}$ & $I_{s p}[\mathrm{~s}]$ & $\rho \mathrm{I}_{s p}\left[\mathrm{sg} / \mathrm{cm}^{3}\right]$ \\
\hline HTPB & WFNA & 4.5 & 265.1 & 360.0 \\
HTPB & LOx & 2.3 & 301.2 & 321.5 \\
HTPB & $\mathrm{H}_{2} \mathrm{O}_{2} 90$ wt. $\%$ & 6.7 & 289.2 & 378.1 \\
Paraffin & WFNA & 5.0 & 264.4 & 359.3 \\
Paraffin & LOx & 2.6 & 301.8 & 321.0 \\
Paraffin & $\mathrm{H}_{2} \mathrm{O}_{2} 90$ wt. $\%$ & 7.4 & 289.0 & 377.7 \\
\hline
\end{tabular}

Before assessing the performances of HMOFs within a paraffin fuel matrix, the $I_{s p}$ was calculated for their pure form and was compared to the values for aluminum and $\mathrm{AB}$. These results are presented for $\mathrm{Co}(\mathbf{A I m})_{2}$ and $\mathrm{Co}(\mathbf{V I m})_{2}$ in Table 6. With all oxidizers studied, pure AB always presented the highest specific impulse. Pure $\mathrm{Co}(\mathbf{A I m})_{2}$ and $\mathrm{Co}(\mathbf{V I m})_{2}$ had 
slightly lower $I_{s p}$ values compared to $\mathrm{AB}$ but were always higher than pure aluminum. As expected, aluminum yielded a higher $\rho I_{s p}$ compared to $\mathrm{AB}$ and the selected HMOFs because of its high density. Interestingly, the $\rho I_{s p}$ of $\mathrm{Co}(\mathbf{A} \mathbf{I m})_{2}$ and $\mathrm{Co}(\mathbf{V I m})_{2}$ was higher than $\mathrm{AB}$ when WFNA or HTP were used as the oxidizer.

Table 6: Theoretical performances of pure MOFs, aluminum and ammonia borane. Equilibrium conditions, chamber pressure of $6.89 \mathrm{MPa}$ and perfect expansion to atmospheric conditions are assumed.

\begin{tabular}{ccccc}
\hline Oxidizer & Fuel & $\mathrm{O} / \mathrm{F}$ & $I_{s p}[\mathrm{~s}]$ & $\rho \mathrm{I}_{s p}\left[\mathrm{sg} / \mathrm{cm}^{3}\right]$ \\
\hline \multirow{3}{*}{ WFNA } & $\mathrm{AB}$ & 1.00 & 288.67 & 297.14 \\
& Aluminum & 2.00 & 231.88 & 411.05 \\
& $\mathrm{Co}(\mathbf{V I m})_{2}$ & 2.50 & 242.01 & 312.35 \\
& $\mathrm{Zn}(\mathbf{V I m})_{2}$ & 2.50 & 241.83 & 316.17 \\
& $\mathrm{Co}(\mathbf{A I m})_{2}$ & 2.25 & 245.24 & 318.50 \\
\hline \multirow{5}{*}{ LOx } & $\mathrm{AB}$ & 1.75 & 316.62 & 309.22 \\
& $\mathrm{Aluminum}$ & 2.25 & 228.32 & 316.79 \\
& $\mathrm{Co}(\mathbf{V I m})_{2}$ & 1.25 & 261.16 & 272.69 \\
& $\mathrm{Zn}(\mathbf{V I m})_{2}$ & 1.25 & 264.04 & 280.21 \\
& $\mathrm{Co}(\mathbf{A I m})_{2}$ & 1.25 & 263.48 & 280.86 \\
\hline \multirow{3}{*}{$\mathrm{H}_{2} \mathrm{O}_{2} 90 \mathrm{wt.} \%$} & $\mathrm{AB}$ & 1.25 & 298.04 & 307.61 \\
& $\mathrm{Aluminum}$ & 2.75 & 269.86 & 431.37 \\
& $\mathrm{Co}(\mathbf{V I m})_{2}$ & 3.75 & 271.13 & 343.13 \\
& $\mathrm{Zn}(\mathbf{V I m})_{2}$ & 3.75 & 270.95 & 346.10 \\
& $\mathrm{Co}(\mathbf{A I m})_{2}$ & 3.50 & 272.80 & 347.81 \\
\hline
\end{tabular}

\subsection{Performance of HMOFs/Paraffin fuels}

In Table 7, the results for HMOF-containing fuels are shown side-by-side with the values calculated for fuel blends containing $\mathrm{AB}$ or aluminum. Figure $7 \mathrm{a}$ and $7 \mathrm{~b}$ present the $I_{s p}$ and $\rho I_{s p}$ of paraffin-based fuels as a function of additive mass loading, with WFNA as the oxidizer. For each additive mass fraction, calculations were done over a broad range of $\mathrm{O} / \mathrm{F}$ ratios and the one yielding the highest $I_{s p}$ was chosen as optimal and reported in the figures and in Table 7. A solid additive mass loading range of 5 wt.\% to 50 wt.\% was considered; the upper-bound was selected because homogeneous blends were experimentally achieved up to $50 \mathrm{wt} . \%$ for a wide variety of additives [32] with higher concentration yielding very brittle fuel blends. However, in practical applications with paraffin fuel matrices, desirable burning characteristics may only be present over a reduced mass loading range. At high mass loads, the inclusion of additives could lead to decreased performances and fuel regression rates. For instance, using $\mathrm{AB}$ as an hypergolic additive, Weismiller et al. reported that at concentration over $20 \%$ by mass in a paraffin or a HTPB fuel matrix, the regression rate was reduced due to a condensed phase created on the surface of the fuel grain during the combustion process [14]. Condensed phase products on the surface of the pellets were also observed with all HMOFs investigated in this paper. This reduction in regression rate is therefore also expected with HMOFs, as heavy combustion products susceptible to condense on the grain may result from 
the presence of $\mathrm{Zn}, \mathrm{Cd}$ and $\mathrm{Co}$ in the fuel. For this reason, a moderate mass loading of 20 wt.\% was selected to investigate the effect of the $\mathrm{O} / \mathrm{F}$ ratio on the $I_{s p}$, with results presented in Table 7 and in Figure 7c when WFNA is used as the oxidizer.

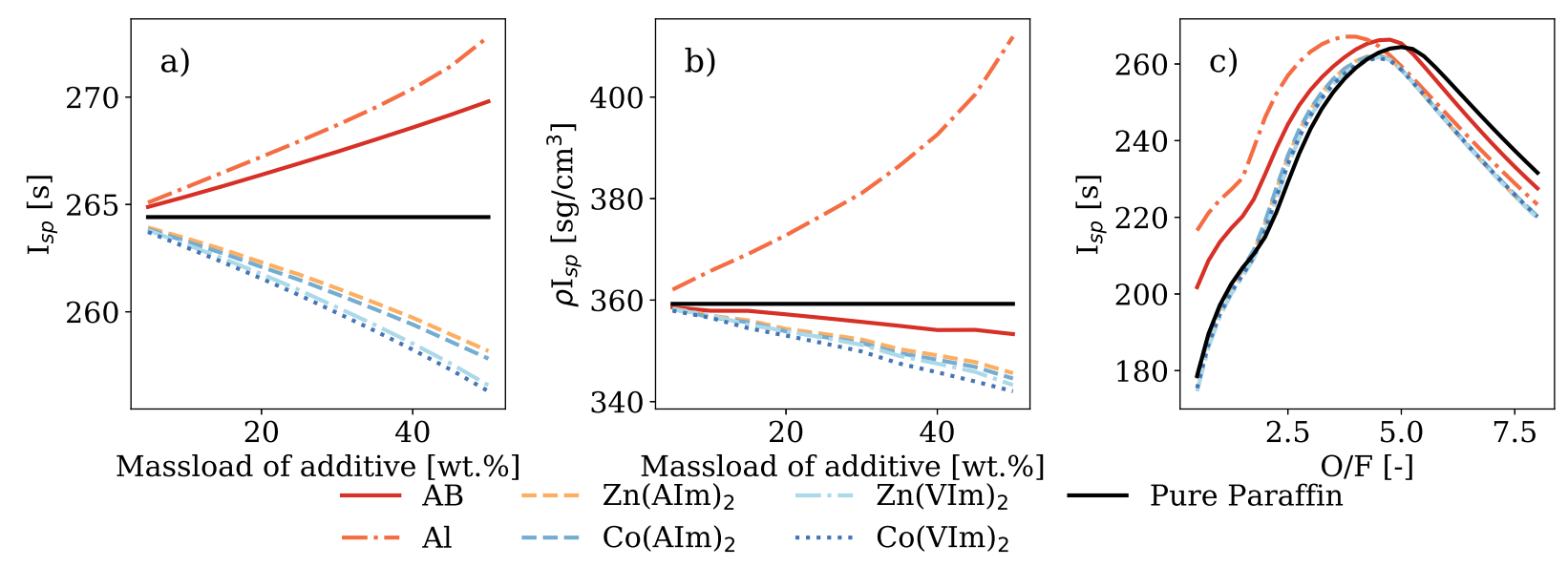

Figure 7: a) Specific impulse as a function of the mass load of additive in a paraffin-based fuel matrix at the optimal $\mathrm{O} / \mathrm{F}$ ratio, b) density specific impulse as a function of the mass load of additive in a paraffin-based fuel matrix and c) theoretical performance at $20 \mathrm{wt} \%$, as a function of oxidizer-to-fuel ratio. Calculated using WFNA as the oxidizer.

As shown in Figures $7 \mathrm{a}$ and $7 \mathrm{~b}$, both $I_{s p}$ and $\rho I_{s p}$ are slightly lower when HMOFs were added to the fuel mixture compared to pure paraffin reacting with WFNA, decreasing approximately linearly with increasing MOF loading. This contrasts with the use of AB, which resulted in a slight increase in $I_{s p}$. The addition of aluminum also yielded an increase in $I_{s p}$, an effect scaling approximately linearly with increased additive mass loading (an increase of $3.3 \%$ at a mass load of $50 \mathrm{wt.} \%$ ). Although there was a minor reduction in $I_{s p}$ on the order of $2.0 \%$ at a mass load of $50 \mathrm{wt} . \%$ for the HMOF-containing fuels compared to pure paraffin as well as paraffin-AB or -Al mixtures, this modest performance tradeoff implied that HMOFs could be useful as additives to impart hypergolicity to an otherwise non-hypergolic fuel.

The $I_{s p}$ and $\rho I_{s p}$ values for the herein explored HMOFs were also calculated using LOx as an oxidizer, with the results shown in Figure 8a, , yielding higher values compared to WFNA. Additionally, the decrease in $I_{s p}$ and $\rho I_{s p}$ values associated with increasing the HMOF mass loading was less pronounced when LOx was used in calculations. For instance, when using LOx the decrease of $I_{s p}$ for $\mathrm{Zn}(\mathbf{A I m})_{2}$ at a fixed mass load of 20 wt.\%, was $2.15 \%$ and $1.18 \%$ compared to $\mathrm{AB}$ and $\mathrm{Al}$, respectively. Corresponding values were $1.53 \%$ and $1.84 \%$, respectively, when WFNA was used. Interestingly, behavior of the calculated $I_{s p}$ as a function of the $\mathrm{O} / \mathrm{F}$ ratio for the $\mathrm{HMOF}$ revealed a very similar combustion behavior to the fuel blends using $\mathrm{AB}$ and $\mathrm{Al}$ as additives, again considering a case with $20 \%$ mass loading (Figure 8c). The curves were all similar in profile, with maxima close to an $\mathrm{O} / \mathrm{F}$ ratio of 2.5 in all cases. Notably, the $I_{s p}$ values for $\mathrm{Zn}(\mathbf{A I m})_{2}$ and $\mathrm{AB}$ are almost equal and just under $300 \mathrm{~s}$ at an $\mathrm{O} / \mathrm{F}$ ratio of approximately 2.5 .

Finally, the $I_{s p}$ and $\rho I_{s p}$ of HMOFs were also calculated using HTP as an oxidizer (Figure 


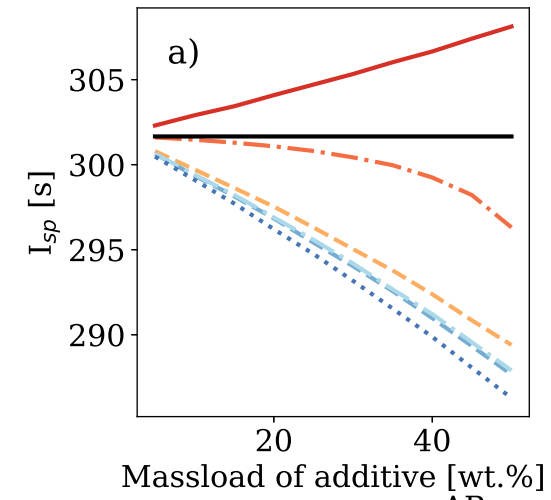

AB

$-=\mathrm{Al}$

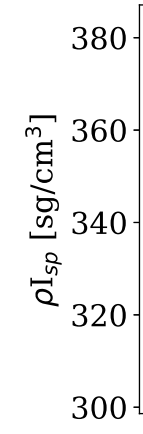

Massload of additive [wt.\%]

$\mathrm{Zn}(\mathrm{AIm})_{2}$

$--\operatorname{Co}(\mathrm{AIm})_{2}$

b)

$\mathrm{Zn}(\mathrm{VIm})_{2}$
$\ldots . . . \mathrm{Co}(\mathrm{VIm})_{2}$

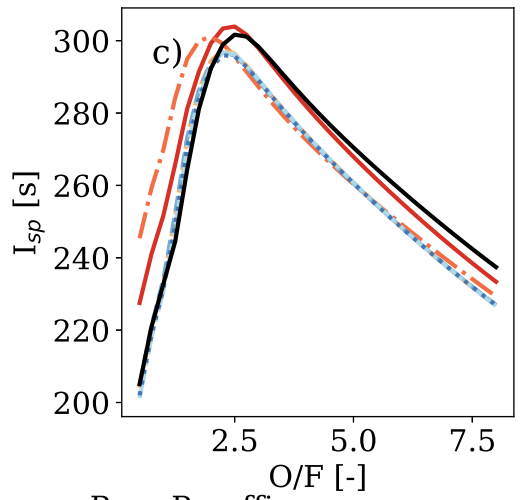

Pure Paraffin

Figure 8: a) Specific impulse as a function of the mass load of additive in a paraffin-based fuel matrix at the optimal $\mathrm{O} / \mathrm{F}$ ratio, b) density specific impulse as a function of the mass load of additive in a paraffin-based fuel matrix and c) theoretical performance at $20 \mathrm{wt} . \%$, as a function of oxidizer-to-fuel ratio. Calculated using LOx as the oxidizer.

9). Overall, the $I_{s p}$ of the hypergols was similar to those obtained when using LOx as an oxidizer. However, there was a smaller drop in $I_{s p}$ with increasing HMOF mass loading. At a mass loading of 20 wt.\%, the decrease was of $0.98 \%$ and of $1.07 \%$ when compared to $\mathrm{AB}$ and Al, respectively, at the same mass loading. However, the $\rho I_{s p}$ with $90 \% \mathrm{HTP}$ was higher than that when using WFNA as the oxidizer. The trends for the variation of the $I_{s p}$ as a function of the $\mathrm{O} / \mathrm{F}$ again showed very similar combustion behavior between the HMOFs, $\mathrm{AB}$ and $\mathrm{Al}$ additives.

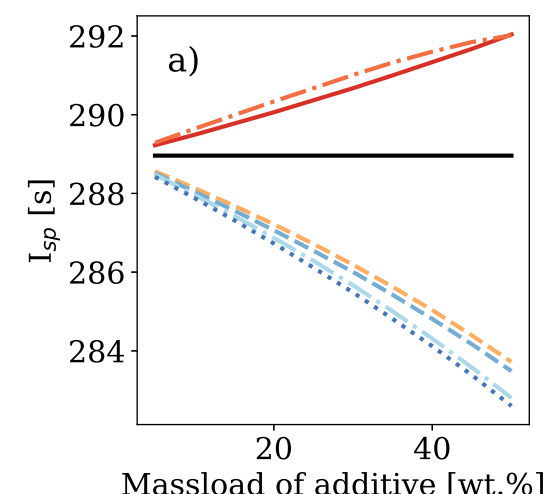

$-=\mathrm{Al}$

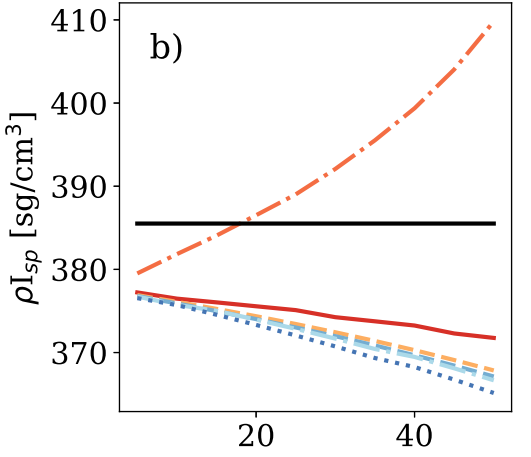

Massload of additive [wt.\%] $\mathrm{Zn}(\mathrm{AIm})_{2}$

$\mathrm{Co}(\mathrm{AIm})_{2}$

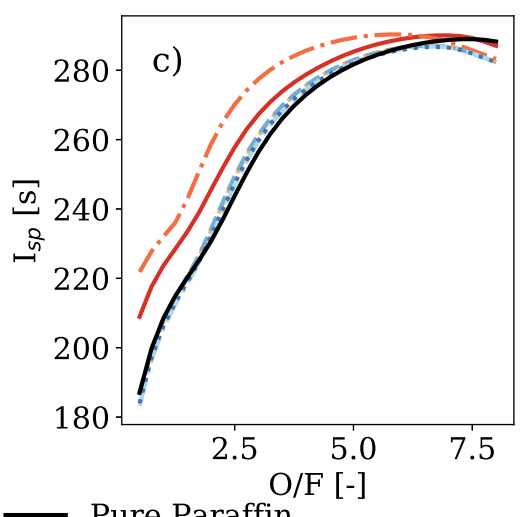

Pure Paraffin

Figure 9: a) Specific impulse as a function of the mass load of additive in a paraffin-based fuel matrix at the optimal $\mathrm{O} / \mathrm{F}$ ratio, b) density specific impulse as a function of the mass load of additive in a paraffin-based fuel matrix and c) theoretical performance at $20 \mathrm{wt} \%$, as a function of oxidizer-to-fuel ratio. Calculated using 90 wt. $\% \mathrm{H}_{2} \mathrm{O}_{2}$ as the oxidizer.

In addition to the $I_{s p}$ and $\rho I_{s p}$ calculated using the NASA-CEA software, the characteristic velocity $\mathrm{C}^{*}$ was also computed. The values are reported in Table 7 for a mass loading of 20 wt.\% in a paraffin matrix, in each case for the $\mathrm{O} / \mathrm{F}$ ratio that provides the maximum $\mathrm{C}^{*}$ 
value. The combustion temperature corresponds to the temperature inside the combustion chamber, whereas the molecular weight was computed at the exit of the nozzle and took into account products in condensed phases.

Table 7: Combustion characteristics of $\mathrm{AB}, \mathrm{Al}$ and HMOFs additives in a paraffin matrix at a mass loading of 20 wt.\%. Equilibrium conditions, chamber pressure of $6.89 \mathrm{MPa}$ and perfect expansion to atmospheric conditions are assumed.

\begin{tabular}{cccccc}
\hline Oxidizer & Additive & $\mathrm{O} / \mathrm{F}$ & $\mathrm{C}^{*}[\mathrm{~m} / \mathrm{s}]$ & $\mathrm{T}_{C}[\mathrm{~K}]$ & $\mathrm{M}_{W}[\mathrm{~g} / \mathrm{mol}]$ \\
\hline \multirow{4}{*}{ WFNA } & AB & 4.1 & 1616.1 & 3105.95 & 24.729 \\
& Aluminum & 3.4 & 1614.5 & 2905.89 & 23.916 \\
& $\mathrm{Co}(\mathbf{V I m})_{2}$ & 4.5 & 1571.8 & 3131.48 & 27.299 \\
& $\mathrm{Zn}(\mathbf{V I m})_{2}$ & 4.5 & 1573.9 & 3139.94 & 27.351 \\
& $\mathrm{Co}(\mathbf{A I m})_{2}$ & 4.0 & 1585.8 & 3123.26 & 26.029 \\
\hline \multirow{5}{*}{ LOx } & $\mathrm{AB}$ & 2.1 & 1836.1 & 3503.93 & 21.942 \\
& Aluminum & 1.7 & 1814.9 & 3623.51 & 22.662 \\
& $\mathrm{Co}(\mathbf{V I m})_{2}$ & 2.4 & 1771.5 & 3660.30 & 26.021 \\
& $\mathrm{Zn}(\mathbf{V I m})_{2}$ & 2.3 & 1781.9 & 3652.10 & 25.388 \\
& $\mathrm{Co}(\mathbf{A I m})_{2}$ & 2.1 & 1789.9 & 3594.36 & 24.232 \\
\hline \multirow{4}{*}{$\mathrm{H}_{2} \mathrm{O}_{2} 90$ wt.\% } & AB & 5.8 & 1754.4 & 3065.08 & 20.805 \\
& $\mathrm{Aluminum}$ & 5.0 & 1749.0 & 3164.18 & 21.496 \\
& $\mathrm{Co}(\mathbf{V I m})_{2}$ & 5.7 & 1730.1 & 3062.22 & 21.441 \\
& $\mathrm{Zn}(\mathbf{V I m})_{2}$ & 5.7 & 1732.4 & 3070.17 & 21.467 \\
& $\mathrm{Co}(\mathbf{A I m})_{2}$ & 5.7 & 1732.2 & 3075.78 & 21.538 \\
\hline
\end{tabular}

The results presented here showed that for the HMOF considered, the $\mathrm{C}^{*}$ and optimal $\mathrm{O} / \mathrm{F}$ were similar. The latter was also comparable to the optimal $\mathrm{O} / \mathrm{F}$ when $\mathrm{AB}$ was used as the additive. Interestingly, when LOx was used as the oxidizer, every paraffinadditive mixtures had a higher $\mathrm{C}^{*}$ than the previously mentioned RP1-LOx $(1774 \mathrm{~m} / \mathrm{s})$ and $\mathrm{N}_{2} \mathrm{O}_{4}-\mathrm{UMDH} / \mathrm{Hydrazine}(1711 \mathrm{~m} / \mathrm{s})$ fuel-oxidizer combinations. When considering $90 \%$ $\mathrm{HTP}$ as the oxidizer, the $\mathrm{C}^{*}$ values for the HMOFS were also higher than for the $\mathrm{N}_{2} \mathrm{O}_{4^{-}}$ $\mathrm{UMDH} /$ Hydrazine combinations.

In general, combustion of paraffin and HMOFs yielded a higher combustion temperature compared to AB, while surpassing aluminum when WFNA was used as the oxidizer. Even though the temperature of combustion of HMOFs was higher than AB, the specific impulse of the latter was higher, primarily due to the lower molecular weight of the exhaust gases.

\section{Discussion}

The presented results demonstrate significant potential of HMOFs as solid, safe to handle and hydrazine- or aminoborane-free additives that can provide hypergolicity to inexpensive, safe and energy-dense solid hydrocarbon fuels required for use in hybrid rocket engines, such as paraffin. The $I_{s p}$ values calculated are closed to those obtained when aluminum metal or $\mathrm{AB}$ is included in the paraffin matrix. For instance, with a moderate mass loading of 20 wt.\% for which good combustion efficiency and regression rates are expected, the relative penalty 
in $I_{s p}$ is not more than $2.15 \%$, compared to the use of hypergolic AB or non-hypergolic $\mathrm{Al}$ additives, when LOx is used as the oxidizer. This slightly higher specific impulse for the hypergolic AB - WNFA combination compared to the HMOFs investigated here is explained by the very high hydrogen content of the former resulting in a lower molecular weight of the combustion products, even though HMOFs have a large heat of combustion. Another minor disadvantage for the use of HMOFs as fuel additives compared to $\mathrm{AB}$ or $\mathrm{Al}$ is the slightly narrower range of $\mathrm{O} / \mathrm{F}$ ratios over which the $I_{s p}$ is close to its optimal value. This means that with HMOF additives in hybrid engines, the oxidizer supply would need to be more carefully controlled and evenly distributed over the fuel grain to ensure optimal combustion, especially when using WFNA. As shown in Figure 7c, the $I_{s p}$ as a function of the $\mathrm{O} / \mathrm{F}$ ratio for HMOF-based paraffin mixtures features a slightly sharper peak between 3.50 and 4.25, as opposed to the broader peaks observed both $\mathrm{AB}$ and aluminum additives. However, this difference between the behavior of the additives is much less pronounced when LOx or 90\% HTP are used as oxidizers.

A hybrid engine relying on HMOFs to provide hypergolicity to paraffin or other hydrocarbon fuel matrices would therefore lose slightly in $I_{s p}$, but gains in having a simple ignition, eliminating the need for more complex external ignition systems. Hypergolic propellants can also add flexibility with regards to possible mission profiles, as they could enable reliable restartability, a feature not possible for solid rockets and adding complexity to nonhypergolic hybrids. A caveat is the difficult ignition observed when the very fine HMOF powders available for the present work were evenly mixed with paraffin. In droplet ignitions test shown here, the mixture composition surrounding MOF particles immersed in the fuel matrix is very lean and as a result the hot outgassing that might initiate the combustion can be quenched by the local overabundance of oxidizer. In engine conditions, careful tuning of the $\mathrm{O} / \mathrm{F}$ ratio during the transient ignition phase of operation could avoid this problem, but this observation highlights the necessity to carefully assess the importance of granulometry of the additives on the hypergolic ignition phenomena in hybrid engines.

Compared to the reference hypergolic additive for hybrid rocket propulsion, $\mathrm{AB}$, HMOFs have the potential to be much easier to mix with paraffin and other hydrocarbons. This is explained by the presence of organic ligands and by their much higher temperature of decomposition, determined by thermogravimetric analysis to be $250-325{ }^{\circ} \mathrm{C}$ [40] for the HMOFs considered here, and 80-100 ${ }^{\circ} \mathrm{C}$ for $\mathrm{AB}$ [42]. HMOFs also have lower toxicity compared to hypergolic fuels based on hydrazine, meaning they offer a safer and less toxic alternative additive that is easier to handle. Finally, HMOFs have the ability to be tailored as needed by including other metals or chemical compounds in their porous structure, making them suitable for a wide range of needs. 


\section{Conclusions}

We have outlined the development of a new materials platform for hypergolic hybrid rocket propulsion, based on metal-organic frameworks (MOFs) as a recently emerged class of hypergolic materials. The hypergolic MOFs exhibit ignition delays and energy content competitive with currently used fuels and additives, and this case study has shown that the presence of $\mathrm{Co}(\mathbf{A I m})_{2}$ and $\mathrm{Co}(\mathbf{V I m})_{2}$ can enable reliable and short ignition delays (below $10 \mathrm{~ms}$ ) for otherwise non-hypergolic paraffin-based fuel. Thermo-chemical simulations reveal that the herein explored hypergolic MOFs could potentially closely match the theoretical specific impulse values of currently used hybrid rocket additives. The values, calculated for paraffin as the fuel matrix in combination with three popular different oxidizers (WFNA, LOx and HTP), were compared to the performance achieved with currently used hypergolic (AB) and non-hypergolic fuel additives (aluminum). Although the calculated $I_{s p}$ values were found to generally slightly decrease with the increase of the mass loading of HMOF in the paraffin fuel matrix, evaluating the change in $I_{s p}$ as a function of oxidizer-to-fuel ratio revealed performance characteristics similar to those predicted for AB- and Al-containing fuel mixtures. The decrease in $I_{s p}$ was found to be no more than $2.15 \%$ for a HMOF mass loading of 20 wt.\%. This minuscule decrease in performance is a very small cost for using a material that is much more thermally stable than $\mathrm{AB}$ as a means to enable hypergolicity within the rocket engine. Further studies will investigate the effect of the hypergolic MOF grain size on the ignition process and its implication on the range of additive mass loadings for which low ignition delays and reliable combustion can be achieved without a significant change in the regression rate of the paraffin fuel.

\section{Acknowledgement}

This work was supported by NSERC Discovery Grant RGPIN-03622-2014; NSERC CGS M, and ES D scholarships (to O.J.); Canadian Space Agency Flights and Fieldwork for the Advancement of Science and Technology (FAST) funding initiative (grant 18FAPOLB17); NCN Sonata grant 2018/31/D/ST5/03619; NSERC RGPIN-2017-06467; NSERC E. W. R. Steacie Memorial Fund (NSERC SMFSU 507347-17); Tier-1 Canada Research Chair Program (to T.F.). We further acknowledge WestGrid (www.westgrid.ca) and Compute Canada (www.computecanada.ca) for providing access to the Cedar supercomputer.

\section{Conflicts of interest}

T.F., R.D.R., H.M.T., J.M.M. are inventors on patent application (no. 62/730,590, from 13 September 2018) related to hypergolic MOFs, which is assigned to ACSYNAM Inc. (Montreal, H1P 1W1, Canada) with T.F., C.M. and R.D.R. as co-owners. 


\section{Supporting Information Available}

Videos of the experiments are available online as supplemental content.

\section{References}

[1] G. Sutton and O. Biblarz, Rocket Propulsion Elements. John Wiley \& Sons, 2010.

[2] J. Malm, "Inclusion of Substances of Very High Concern in the Candidate List (Decision of the European Chemicals Agency), Document \# ED/31/2011," tech. rep., European Chemicals Agency, 2011.

[3] R. V. Petrescu, R. Aversa, B. Akash, R. Bucinell, J. Corchado, F. Berto, M. Mirsayar, A. Apicella, F. I. T. Petrescu, B. Akash, R. Bucinell, J. Corchado, A. Apicella, and F. I. T. Petrescu, "Modern Propulsions for Aerospace-A Review," Journal of Aircraft and Spacecraft Technology, vol. 1, pp. 1-8, jan 2017.

[4] T. Harrison, A. Hunter, K. Johnson, and T. Roberts, Implication of Ultra-Low-Cost Access to Space. New York, USA: Rowman \& Littlefield, 2017.

[5] R. W. Conversano, D. M. Goebel, R. R. Hofer, I. G. Mikellides, and R. E. Wirz, "Performance Analysis of a Low-Power Magnetically Shielded Hall Thruster: Experiments," Journal of Propulsion and Power, vol. 33, pp. 975-983, jul 2017.

[6] J. M. Bergthorson, Y. Yavor, J. Palecka, W. Georges, M. Soo, J. Vickery, S. Goroshin, D. L. Frost, and A. J. Higgins, "Metal-water combustion for clean propulsion and power generation," Applied Energy, vol. 186, pp. 13-27, jan 2017.

[7] D. Ma, J. Murray, and J. N. Munday, "Controllable Propulsion by Light: Steering a Solar Sail via Tunable Radiation Pressure," Advanced Optical Materials, vol. 5, p. 1600668, feb 2017.

[8] National Aeronautics and Space Administration, Reference Guide to The International Space Station. 2015.

[9] B. A. Palaszewski, M. L. Meyer, L. Johnson, D. M. Goebel, H. White, and D. J. Coote, "In-Space Chemical Propulsion System Roadmap," in Chemical Rocket Propulsion, pp. 655-671, Springer, 2017.

[10] M. C. Vilela Salgado, M. C. N. Belderrain, and T. C. Devezas, "Space Propulsion: a Survey Study About Current and Future Technologies," Journal of Aerospace Technology and Management, vol. 10, pp. 1-23, feb 2018.

[11] A. Mazzetti, L. Merotto, and G. Pinarello, "Paraffin-based hybrid rocket engines applications: A review and a market perspective," Acta Astronautica, vol. 126, pp. 286-297, sep 2016. 
[12] S. G. Kulkarni, V. S. Bagalkote, S. S. Patil, U. P. Kumar, and V. A. Kumar, "Theoretical Evaluation and Experimental Validation of Performance Parameters of New Hypergolic Liquid Fuel Blends with Red Fuming Nitric Acid as Oxidizer," Propellants, Explosives, Pyrotechnics, vol. 34, pp. 520-525, dec 2009.

[13] L. He, G.-H. Tao, D. A. Parrish, and J. M. Shreeve, "Nitrocyanamide-Based Ionic Liquids and Their Potential Applications as Hypergolic Fuels," Chemistry - A European Journal, vol. 16, pp. 5736-5743, may 2010.

[14] M. Weismiller, T. Connell, G. Risha, and R. Yetter, "Characterization of Ammonia Borane (NH3BH3) Enhancement to a Paraffin Fueled Hybrid Rocket System," in 46st AIAA/SAE/ASEE Joint Propulsion Conference, (Nashville, TN), pp. 1-12, American Institute of Aeronautics and Astronautics, 2010.

[15] Y. Zhang, H. Gao, Y.-H. Joo, and J. M. Shreeve, "Ionic Liquids as Hypergolic Fuels," Angewandte Chemie International Edition, vol. 50, pp. 9554-9562, oct 2011.

[16] Y. Zhang and J. M. Shreeve, "Dicyanoborate-Based Ionic Liquids as Hypergolic Fluids," Angewandte Chemie International Edition, vol. 50, pp. 935-937, jan 2011.

[17] S. Schneider, T. Hawkins, Y. Ahmed, M. Rosander, L. Hudgens, and J. Mills, "Green Bipropellants: Hydrogen-Rich Ionic Liquids that Are Hypergolic with Hydrogen Peroxide," Angewandte Chemie International Edition, vol. 50, pp. 5886-5888, jun 2011.

[18] P. V. Ramachandran, A. S. Kulkarni, M. A. Pfeil, J. D. Dennis, J. D. Willits, S. D. Heister, S. F. Son, and T. L. Pourpoint, "Amine-Boranes: Green Hypergolic Fuels with Consistently Low Ignition Delays," Chemistry - A European Journal, vol. 20, pp. 1686916872 , dec 2014.

[19] M. Pfeil, A. S. Kulkarni, P. V. Ramachandran, S. F. Son, and S. D. Heister, "Solid Amine-Boranes as High-Performance and Hypergolic Hybrid Rocket Fuels," Journal of Propulsion and Power, vol. 32, pp. 23-31, jan 2016.

[20] G. P. Rachiero, H. M. Titi, and R. D. Rogers, "Versatility and remarkable hypergolicity of exo-6, exo-9 imidazole-substituted nido-decaborane," Chemical Communications, vol. 53, no. 55, pp. 7736-7739, 2017.

[21] J. Yu, T. N. Jensen, W. K. Lewis, C. E. Bunker, S. P. Kelley, R. D. Rogers, O. M. Pryor, S. D. Chambreau, G. L. Vaghjiani, and S. L. Anderson, "Combustion Behavior of High Energy Density Borane-Aluminum Nanoparticles in Hypergolic Ionic Liquids," Energy \& Fuels, vol. 32, pp. 7898-7908, jul 2018.

[22] A. K. Chinnam, N. Petrutik, K. Wang, A. Shlomovich, O. Shamis, D. S. Tov, M. Sućeska, Q.-L. Yan, R. Dobrovetsky, and M. Gozin, "Effects of closo -icosahedral periodoborane salts on hypergolic reactions of $70 \%$ H 2 O 2 with energetic ionic liquids," Journal of Materials Chemistry A, vol. 6, no. 41, pp. 19989-19997, 2018. 
[23] K. Wang, A. K. Chinnam, N. Petrutik, E. P. Komarala, Q. Zhang, Q.-L. Yan, R. Dobrovetsky, and M. Gozin, "Iodocuprate-containing ionic liquids as promoters for green propulsion," Journal of Materials Chemistry A, vol. 6, no. 45, pp. 22819-22829, 2018.

[24] H. M. Titi, M. Arhangelskis, G. P. Rachiero, T. Friščić, and R. D. Rogers, "Hypergolic Triggers as Co-crystal Formers: Co-crystallization for Creating New Hypergolic Materials with Tunable Energy Content," Angewandte Chemie International Edition, vol. 58, pp. 18399-18404, dec 2019.

[25] V. K. Bhosale, J. Jeong, and S. Kwon, "Ignition of boron-based green hypergolic fuels with hydrogen peroxide," Fuel, vol. 255, p. 115729, 2019.

[26] K. Wang, T. Liu, Y. Jin, S. Huang, N. Petrutik, D. Shem-Tov, Q.-L. Yan, M. Gozin, and Q. Zhang, "“Tandem-action” ferrocenyl iodocuprates promoting low temperature hypergolic ignitions of "green" EIL-H 2 O 2 bipropellants," Journal of Materials Chemistry $A$, vol. 8, no. 29, pp. 14661-14670, 2020.

[27] Q.-Y. Wang, J. Wang, S. Wang, Z.-Y. Wang, M. Cao, C.-L. He, J.-Q. Yang, S.-Q. Zang, and T. C. W. Mak, "o -Carborane-Based and Atomically Precise Metal Clusters as Hypergolic Materials," Journal of the American Chemical Society, vol. 142, pp. 1201012014 , jul 2020.

[28] L. Liang, Y. Zhong, Y. Xu, G. Lei, J. Chen, H. Huang, Z. Li, J. Zhang, and T. Zhang, "Cyanoborohydride (CBH)-based hypergolic coordination compounds for versatile fuels," Chemical Engineering Journal, vol. 426, p. 131866, dec 2021.

[29] J. Jeong, V. K. Bhosale, and S. Kwon, "Ultrafast igniting, low toxicity hypergolic hybrid solid fuels and hydrogen peroxide oxidizer," Fuel, vol. 286, p. 119307, 2021.

[30] R. Masse, M. Allen, R. Spores, and E. A. Driscoll, "Af-m315e propulsion system advances and improvements," in 52nd AIAA/SAE/ASEE Joint Propulsion Conference, (Salt Like City, UT), pp. 1-10, American Institute of Aeronautics and Astronautics, jul 2016 .

[31] R. Amrousse, T. Katsumi, N. Azuma, and K. Hori, "Hydroxylammonium nitrate (HAN)-based green propellant as alternative energy resource for potential hydrazine substitution: From lab scale to pilot plant scale-up," Combustion and Flame, vol. 176, pp. 334-348, feb 2017.

[32] A. Karabeyoglu and U. Arkun, "Evaluation of Fuel Additives for Hybrid Rockets and SFRJ Systems," in 50th AIAA/ASME/SAE/ASEE Joint Propulsion Conference, (Cleveland, $\mathrm{OH}$ ), pp. 1-41, American Institute of Aeronautics and Astronautics, jul 2014. 
[33] M. Pfeil, Solid amine-boranes as high performance hypergolic hybrid rocket fuels. PhD thesis, Purdue University, oct 2014.

[34] B. Elzein, O. Jobin, and E. Robert, "Reducing the ignition delay of hypergolic hybrid rocket fuels," Journal of Propulsion and Power, vol. 37, no. 1, pp. 77-85, 2021.

[35] H.-C. J. Zhou and S. Kitagawa, "Metal-Organic Frameworks (MOFs)," Chemical Society Reviews, vol. 43, pp. 5415-5418, jul 2014.

[36] H.-C. Zhou, J. R. Long, and O. M. Yaghi, "Introduction to Metal-Organic Frameworks," Chemical Reviews, vol. 112, pp. 673-674, feb 2012.

[37] S. L. James, "Metal-organic frameworks," Chemical Society Reviews, vol. 32, p. 276, aug 2003.

[38] Y. Cui, B. Li, H. He, W. Zhou, B. Chen, and G. Qian, "Metal-Organic Frameworks as Platforms for Functional Materials," Accounts of Chemical Research, vol. 49, pp. 483493, mar 2016.

[39] H. M. Titi, M. Arhangelskis, A. D. Katsenis, C. Mottillo, G. Ayoub, J.-L. Do, A. M. Fidelli, R. D. Rogers, and T. Friščić, "Metal-Organic Frameworks as Fuels for Advanced Applications: Evaluating and Modifying the Combustion Energy of Popular MOFs," Chemistry of Materials, vol. 31, pp. 4882-4888, jul 2019.

[40] H. M. Titi, J. M. Marrett, G. Dayaker, M. Arhangelskis, C. Mottillo, A. J. Morris, G. P. Rachiero, T. Friščić, and R. D. Rogers, "Hypergolic zeolitic imidazolate frameworks (ZIFs) as next-generation solid fuels: Unlocking the latent energetic behavior of ZIFs," Science Advances, vol. 5, pp. 1-8, apr 2019.

[41] J. T. Hughes, T. D. Bennett, A. K. Cheetham, and A. Navrotsky, "Thermochemistry of Zeolitic Imidazolate Frameworks of Varying Porosity," Journal of the American Chemical Society, vol. 135, pp. 598-601, jan 2013.

[42] F. Baitalow, J. Baumann, G. Wolf, K. Jaenicke-Rößler, and G. Leitner, "Thermal decomposition of $\mathrm{b}-\mathrm{n}-\mathrm{h}$ compounds investigated by using combined thermoanalytical methods," Thermochimica Acta, vol. 391, no. 1, pp. 159-168, 2002.

[43] B. Evans, N. Favorito, G. Risha, E. Boyer, R. Wehrman, and K. Kuo, "Characterization of nano-sized energetic particle enhancement of solid-fuel burning rates in an x-ray transparent hybrid rocket engine," in 40th AIAA/ASME/SAE/ASEE Joint Propulsion Conference and Exhibit, (Fort Lauderdale, FL), pp. 1-12, American Institute of Aeronautics and Astronautics, jul 2012.

[44] S. Li, H. Gao, and J. M. Shreeve, "Borohydride ionic liquids and borane/ionic-liquid solutions as hypergolic fuels with superior low ignition-delay times," Angewandte Chemie International Edition, vol. 53, no. 11, pp. 2969-2972, 2014. 
[45] M. Barrere, A. Jaumotte, B. Fraeijis de Veubeke, and J. Vandenkerckhove, Rocket Propulsion (Propulsion de la fusée). Elsevier, 1960.

[46] K. J. Stober, B. J. Cantwell, and R. A. L. Otaibi, "Hypergolic Ignition of Lithium-Aluminum-Hydride-Doped Paraffin Wax and Nitric Acid," Journal of Propulsion and Power, vol. 36, no. 3, 2020.

[47] S. J. Clark, M. D. Segall, C. J. Pickard, P. J. Hasnip, M. I. J. Probert, K. Refson, and M. C. Payne, "First principles methods using CASTEP," Zeitschrift für Kristallographie - Crystalline Materials, vol. 220, no. 5-6, pp. 567-570, 2005.

[48] K. Burke, J. P. Perdew, and M. Ernzerhof, "Why the generalized gradient approximation works and how to go beyond it," International Journal of Quantum Chemistry, vol. 61, no. 2, pp. 287-293, 1997.

[49] S. Grimme, "Semiempirical GGA-type density functional constructed with a long-range dispersion correction," Journal of Computational Chemistry, vol. 27, no. 15, pp. 17871799, 2006.

[50] T. Björkman, "CIF2Cell: Generating geometries for electronic structure programs," Computer Physics Communications, vol. 182, no. 5, pp. 1183-1186, 2011.

[51] S. Gordon and B. J. Mcbride, "Computer Program for Calculation of Complex Chemical Equilibrium Compositions and Applications - I Analysis," NASA RP-1311, October 1994. 